\title{
Non-high-density lipoprotein cholesterol/ high-density lipoprotein cholesterol ratio serve as a predictor for coronary collateral circulation in chronic total occlusive patients
}

\author{
Ya Li ${ }^{1}$, Xin Chen ${ }^{2}$, Shu Li ${ }^{1}$, Yulin Ma ${ }^{3}$, Jialing $\mathrm{Li}^{1}$, Mingying $\mathrm{Lin}^{1}$ and Jing Wan ${ }^{1 *}$
}

\begin{abstract}
Objective: The present study investigated the potential correlation between non-high-density lipoprotein cholesterol/high-density lipoprotein cholesterol ratio (non-HDL-C/HDL) and the formation of coronary collateral circulation (CCC) in coronary artery disease cases with chronic total occlusive (CTO) lesions.

Methods: Two experienced cardiologists identified and selected patients with CTO lesions for retrospective analysis. The 353 patients were divided into a CCC poor formation group (Rentrop 0-1 grade, $\mathrm{n}=209$ ) and a CCC good formation group (Rentrop 2-3 grade, $n=144$ ) based on the Cohen-Rentrop standard. A comparison of non-HDL-C/HDL ratios between the two groups was performed. The Spearman test was used to obtain the correlation between the cholesterol ratio and Rentrop grade. Independent predictors of CCC were analyzed using logistic regression. Receiver operating characteristic (ROC) curve analysis was also performed to quantify the predictive value of research indicator.

Results: The non-HDL-C/HDL ratio in the CCC poor formation group was elevated markedly compared to the CCC good formation group $[(3.86 \pm 1.40)$ vs $(3.31 \pm 1.22), P=0.000]$. The Spearman test results indicated that non-HDL$\mathrm{C} / \mathrm{HDL}$ negatively correlated with Rentrop grade $(r=-0.115, P=0.030)$. Multivariate logistic regression analysis showed that non-HDL-C/HDL ratio was an independent predictor of CCC formation $(\mathrm{OR}=1.195,95 \% \mathrm{Cl}=1.020-1.400$, $P=0.027)$. The area under the curve of ROC for detecting CCC poor formation was 0.611 (95\% Cl: 0.551-0.671, $P=0.000$ ) with an optimal cut-off value of 2.77 .
\end{abstract}

Conclusion: Non-HDL-C/HDL negatively correlated with the formation of CCC and served as an independent predictor of CCC formation, which may be used as a biomarker for the evaluation of CCC.

Keywords: Non-HDL-C/HDL, Coronary collateral circulation, Chronic total occlusive disease

\section{Introduction}

Chronic total occlusions (CTOs) are an important subtype of coronary artery disease (CAD) and pose a great threat to a patient's prognosis because it remains

\footnotetext{
*Correspondence: wanjing_zn@163.com

1 Department of Cardiology, Zhongnan Hospital of Wuhan University, No

169 Donghu Road, Wuchang District, Wuhan 430071, Hubei Province,

China

Full list of author information is available at the end of the article
}

prevalent in approximately one third of cases with CAD $[1,2]$. CTO refers to a lesion in which the coronary artery is completely occluded or almost completely occluded for more than 3 months [3]. A system of coronary collateral circulation (CCC) is found in most CTO patients. These vessels provide the myocardium with another blood supply that may prevent myocardial necrosis and help improve left ventricular function [4, 5]. Previous studies suggested that well-formed CCC in patients with CTO

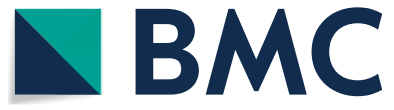

(c) The Author(s) 2021. Open Access This article is licensed under a Creative Commons Attribution 4.0 International License, which permits use, sharing, adaptation, distribution and reproduction in any medium or format, as long as you give appropriate credit to the original author(s) and the source, provide a link to the Creative Commons licence, and indicate if changes were made. The images or other third party material in this article are included in the article's Creative Commons licence, unless indicated otherwise in a credit line to the material. If material is not included in the article's Creative Commons licence and your intended use is not permitted by statutory regulation or exceeds the permitted use, you will need to obtain permission directly from the copyright holder. To view a copy of this licence, visit http://creativecommons.org/licenses/by/4.0/. The Creative Commons Public Domain Dedication waiver (http://creativeco mmons.org/publicdomain/zero/1.0/) applies to the data made available in this article, unless otherwise stated in a credit line to the data. 
reduced myocardial infarcts and improved the prognosis of patients [6,7]. Therefore, it will be worthwhile to understand the mechanisms and influencing factors of the formation of CCC to identify new biomarkers. The existing evaluation methods (e.g., Collateral Flow Index (CFI), contrast echocardiography, and myocardial perfusion imaging) for the formation of CCC in patients with CTO are relatively complicated and expensive. Thus, an easy and feasible method for evaluating or predicting CCC formation is needed.

Dyslipidemia is tightly related to atherosclerosis. In clinical practice, decrease concentration of low-density lipoprotein cholesterol (LDL-C), non-high-density lipoprotein cholesterol (non-HDL-C), and triglyceride (TG) and increase of high-density lipoprotein cholesterol (HDL-C) concentration are commonly used as parameters in lipid-lowering strategies. Clinical physicians examined the non-HDL-C/HDL, this index represents the ratio of cholesterol contained in all of the atherosclerosis-promoting particles (non-HDL-C) and cholesterol contained in all the anti-atherosclerosis particles (HDLC) in the serum, to evaluate lipid-related diseases. Some findings indicated that this cholesterol ratio was a better index than apolipoprotein B/apolipoprotein A1 and conventional single lipid parameter for identifying lipidrelated diseases, such as insulin resistance, metabolic syndrome and CAD $[8,9]$. However, few studies focused on the role of non-HDL-C/HDL ratio for predicting CCC formation in patients with CTO. The present study estimated the association between the non-HDL-C/HDL ratio and the formation of $\mathrm{CCC}$.

\section{Patients and methods}

\section{Study population}

Coronary angiography was performed in the Department of Cardiology, Zhongnan Hospital of Wuhan University from January 2013 to September 2018, and 353 patients who met the criteria were enrolled in this study. CTO diagnostic criteria were according to the American College of Cardiology Foundation (ACCF)/American Heart Association (AHA)/Society for Cardiovascular Angiography and Interventions (SCAI) of 2013[10]: the coronary vascular cavity was completely occluded because of thrombosis and the repeated organization of coronary arteries because of atherosclerotic lesions, and the course of the occlusion exceeded three months. Coronary angiography showed that three main coronary arteries (left anterior descending artery (LAD), left circumflex artery (LCA) and right coronary artery (RCA)) had at least one branch with stenosis $\geq 90 \%$.

Exclusion criteria: Acute myocardial infarction in the past three months, previous coronary stent placement or Coronary artery bypass graft within three months, coronary artery myocardial bridge and/or congenital coronary arterial malformation, cardiomyopathy or decompensated cardiac dysfunction or other severe medical disease (liver and kidney disease, infectious diseases and thyroid disease) and patients with long-term lipid-affecting drug use history. The Medical Ethics Committee of Zhongnan Hospital approved this study.

\section{Assessment of coronary collateral circulation and group}

Two interventional experts performed the coronary angiography based on the Judkin method using a radial or femoral approach. The degree of stenosis of main coronary arteries (LAD, LCX or RCA) was evaluated. Multivessel lesion is generally defined by the presence of a $.50 \%$ stenotic lesion (by visual angiographic assessment) in two or more major epicardial coronary arteries (LAD, LCX or RCA). CCC formation was evaluated using the Cohen-Rentrop criteria [11]: Grade 0, without any collateral artery filling; Grade 1, filling of the side branches of the occluded artery, and contrast agent cannot reach the epicardial vessel; Grade 2, the epicardial vessel is partially filled; and Grade 3, the epicardial vessel is completely filled by collaterals. The participants were divided into a well-formed CCC group (Rentrop grade 2-3) and a poorly formed CCC group (Rentrop grade $0-1$ ).

\section{Laboratory measurements}

The patients fasted for more than $10 \mathrm{~h}$ before blood was collected from the antecubital vein. The serum was collected after the blood has spontaneously coagulated and been centrifuged, measurement of serum lipids was performed using an automated biochemical analyzer (Beckman Coulter, AU5800, USA) and an enzymatic reaction method. Non-HDL-C equals serum total cholesterol (TC) minus serum HDL. Non-HDL-C/HDL was calculated by dividing the non-HDL-C with HDL.

\section{Statistical analysis}

The Kolmogorov-Smirnov test was used to identify whether the measurement data were normally distributed. The continuous data in a normal distribution are represented as the means \pm SD. Student's t-test was used to identify differences between two groups. Nonnormally distributed continuous variables are represented as medians (interquartile ranges), and the difference between groups was analyzed using the Mann-Whitney U-test. The counted variables are expressed in percentages and compared using the $X^{2}$ test. One-way ANOVA was performed to compare the categories of Rentrop grades. The Spearman test was performed to describe correlations of research indicators with the Rentrop grade. To identify the affecting factors of CCC formation, a regressed model of 
multivariate logistic was used. A receiver operating characteristic (ROC) curve was analyzed to assess the research indicator for predicting CCC poor formation. The results are expressed within 95\% confidence intervals $(\mathrm{CI})$, and a $P<0.05$ represented statistical significance. All the statistical variables were obtained using IBM SPSS 23.0 software (IBM Corp, Armonk, New York, USA).

\section{Results}

\section{Basic clinical information and characteristics of patients}

According to the evaluation of CCC formation, 144 cases had well-formed CCC, and 209 cases had poorly formed CCC. Table 1 shows that the CCC good

Table 1 Basic clinical characteristics of the study participants

\begin{tabular}{|c|c|c|c|}
\hline Variables & $\begin{array}{l}\text { CCC good } \\
\text { formation group } \\
(n=144)\end{array}$ & $\begin{array}{l}\text { CCC poor } \\
\text { formation group } \\
(n=209)\end{array}$ & $P$ value \\
\hline Age & $63.27 \pm 10.78$ & $61.52 \pm 12.16$ & 0.165 \\
\hline Gender [man (\%)] & $122(41.9)$ & $169(58.1)$ & 0.349 \\
\hline Smoking & $69(41.3)$ & $98(58.7)$ & 0.914 \\
\hline Diabetes & $38(38.0)$ & $62(62.0)$ & 0.549 \\
\hline Hypertension & $95(43.6)$ & $123(56.4)$ & 0.183 \\
\hline $\begin{array}{l}\text { Coronary artery } \\
\text { disease }\end{array}$ & $3(33.3)$ & $6(66.7)$ & 0.645 \\
\hline drinking & $41(41.4)$ & $58(58.6)$ & 0.904 \\
\hline aspirin & $4(33.3)$ & $8(66.7)$ & 0.768 \\
\hline$\beta$-blockers & $8(38.1)$ & $13(61.9)$ & 0.795 \\
\hline ACEI/ARB & $22(34.4)$ & $42(65.6)$ & 0.264 \\
\hline $\mathrm{TC}(\mathrm{mmol} / \mathrm{l})$ & $4.40 \pm 1.01$ & $4.56 \pm 1.13$ & 0.179 \\
\hline $\begin{array}{l}\mathrm{TG}(\mathrm{M}(P 25, P 75) \\
\mathrm{mmoL} / \mathrm{L})\end{array}$ & $1.76(0.97,2.10)$ & $2.16(1.12,2.35)$ & 0.058 \\
\hline $\mathrm{HDL}(\mathrm{mmol} / \mathrm{l})$ & $1.07(0.86,1.23)$ & $0.97(0.80,1.11)$ & $0.002^{* *}$ \\
\hline LDL (mmol/l) & $2.73 \pm 0.77$ & $2.83 \pm 0.87$ & 0.251 \\
\hline $\mathrm{LP}(\mathrm{a})(\mathrm{M}, \mathrm{mg} / \mathrm{L})$ & $219.65(60.57,276.3)$ & $184.56(65.7,221)$ & 0.288 \\
\hline $\begin{array}{l}\text { Non-HDL-C } \\
(\mathrm{mmol} / \mathrm{l})\end{array}$ & $3.33(2.69,3.90)$ & $3.59(2.75,4.30)$ & 0.057 \\
\hline Non-HDL-C/HDL & $3.31 \pm 1.22$ & $3.86 \pm 1.40$ & $0.000^{*}$ \\
\hline \multicolumn{4}{|l|}{ Occlusive vessel (\%) } \\
\hline $\begin{array}{l}\text { Multiple vessels } \\
\text { lesions }\end{array}$ & $30(62.5)$ & $18(37.5)$ & $0.001^{*}$ \\
\hline LAD & $39(38.2)$ & $63(61.8)$ & 0.552 \\
\hline LCX & $21(28.4)$ & $53(71.6)$ & $0.015^{* *}$ \\
\hline RCA & $54(41.9)$ & $75(58.1)$ & 0.757 \\
\hline \multicolumn{4}{|c|}{$\begin{array}{l}\mathrm{CCC} \text {, coronary collateral circulation; } \mathrm{ACEl} \text {, angiotension converting enzyme } \\
\text { inhibitors;ARB, angiotensin receptor blocker; TC, total cholesterol; TG, } \\
\text { triglyceride; } \mathrm{HDL} \text {, high-density lipoprotein; } \mathrm{LDL} \text {, low-density lipoprotein; non- } \\
\mathrm{HDL}-\mathrm{C} \text {, non-high-density lipoprotein cholesterol; } \mathrm{TC} / \mathrm{HDL} \text {, total cholesterol / } \\
\text { high-density lipoprotein cholesterol ratio; Non-HDL-C/HDL, non-high-density } \\
\text { lipoprotein cholesterol /high-density lipoprotein cholesterol ratio; LAD, left } \\
\text { anterior descending artery; LCX, left circumflex artery; RCA, right coronary artery }\end{array}$} \\
\hline$<0.01, * * P<0.05$ & & & \\
\hline
\end{tabular}

formation group had a higher percentage of multiple vessel lesions and HDL-C was elevated in CCC good formation group. For the CCC poor formation group, the percentages of left circumflex artery occlusion and non-HDL-C/HDL [( $3.86 \pm 1.40)$ vs $(3.31 \pm 1.22)$, $P=0.000]$ were elevated compared to the CCC good formation group.

\section{Relationships between non-HDL-C/HDL ratio and Rentrop grade}

Spearman correlation analysis was performed on the non-HDL-C/HDL ratios with the Rentrop grade. Negatively correlated results were obtained between the non-HDL-C/HDL ratio and Rentrop grade $(\mathrm{r}=-0.115$, $P=0.030)$. The non-HDL-C/HDL ratio in Rentrop 3 $(3.14 \pm 1.18)$ was significantly lower than Rentrop 0 ( $3.85 \pm 1.41)(P=0.001)$ and Rentrop 1 ( $3.90 \pm 1.36)$ $(P=0.004)$, The non-HDL-C/HDL ratio in Rentrop 2 $(3.41 \pm 1.24)$ was also significantly lower than Rentrop 0 $(P=0.012)$ and Rentrop $1(P=0.036)$. The ratio of nonHDL-C/HDL between Rentrop 0 and Rentrop 1, Rentrop 2 and Rentrop 3 showed no significant differences. $(P>0.05)$ (Fig. 1).

\section{Analysis of risk factors for coronary collateral circulation}

The baseline variables that are considered clinically relevant or showed a univariate relationship with the results were used in the multivariate model to evaluate the potential predictors of CCC. The good or poor formation of CCC was used as dependent variable, and candidate factors with a $P$ value $<0.2$ in univariate analysis (Table 1 ) were included in the multivariable analysis. The results showed that multiple vessel lesions and non-HDL-C/

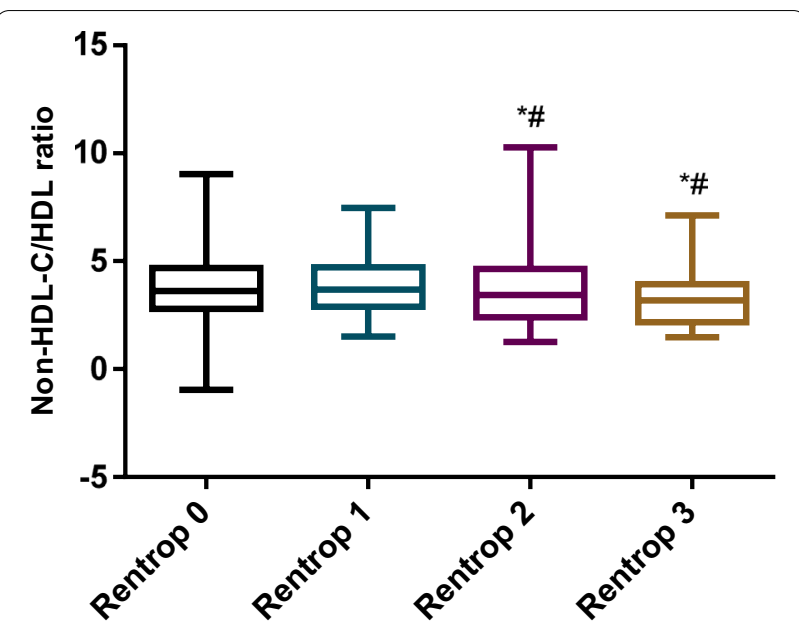

Fig. 1 Non-HDL-C/HDL ratio value of patients in each Rentrop grade. Note: ${ }^{*} P<0.05$ (compared with Rentrop 0 grade). ${ }^{\#} P<0.05$ (compared with Rentrop 1 grade) 
Table 2 Multivariable logistic regression analysis of independent factors for CCC

\begin{tabular}{lrllll}
\hline Variables & \multicolumn{1}{l}{ B } & Wald & $\boldsymbol{P}$ value & OR & $\mathbf{9 5 \%} \mathbf{C l}$ \\
\hline Age & -0.666 & 0.506 & 0.908 & 0.999 & $0.979-1.019$ \\
Non-HDL-C/HDL & 0.178 & 4.879 & $0.027^{* *}$ & 1.195 & $1.020-1.400$ \\
Hypertension & 0.195 & 1.619 & 0.203 & 1.343 & $0.853-2.115$ \\
Multiple vessels lesions & 0.983 & 8.943 & $0.003^{* *}$ & 2.671 & $1.403-5.088$ \\
LCX & -0.671 & 5.154 & $0.023^{* *}$ & 0.511 & $0.286-0.912$ \\
\hline
\end{tabular}

Non-HDL-C/HDL, non-high-density lipoprotein cholesterol/high-density lipoprotein cholesterol ratio; LCX, left circumflex artery

${ }^{*} P<0.01,{ }^{* *} P<0.05$

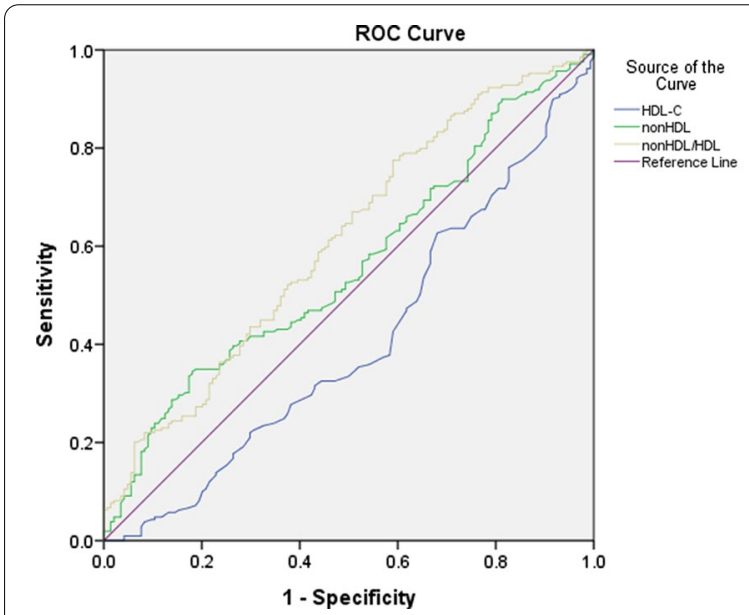

Fig. 2 Receiver operating characteristic (ROC) analysis of the relationship between the non-HDL-C/HDL-C ratio and the poor formation of CCC

HDL were independent risk factors for CCC, non-HDL$\mathrm{C} / \mathrm{HDL} \quad(\mathrm{OR}=1.195,95 \% \mathrm{CI}=1.020-1.400, \quad \mathrm{P}=0.027)$ was significantly associated with the risk of CCC poor formation, the contribution to the risk of poor CCC formation is nearly 1.2 times with per one unit increase in non-HDL-C/HDL (Table 2).

\section{Non-HDL-C/HDL prediction of CCC poor formation with ROC curves}

The ROC analysis revealed that the area under the curve(AUC) of non-HDL-C and HDL for detecting CCC poor formation were 0.560 (95\% CI: $0.500-0.620$, $P=0.056)$ and 0.405 (95\% CI: $0.344-0.465, P=0.002$ ), respectively. However, AUC of the non-HDL-C/HDL ratio for detecting CCC poor formation was 0.611 (95\%
CI: $0.551-0.671, P=0.000$ ), the expected non-HDL-C/ HDL ratio was better than non-HDL-C or HDL for predicting CCC poor formation. The optimal cut-off point was 2.77 (Youden index 0.185 ), with $77.5 \%$ sensitivity and $41 \%$ specificity (Fig. 2 ).

\section{Study strengths and limitations}

The present study demonstrated that in CTO patients 1) the non-HDL-C/HDL ratio in the CCC poor formation group was significantly elevated compared to the CCC good formation group and 2) the non-HDL-C/HDL ratio negatively correlated with the formation of $\mathrm{CCC}$ and may be developed as an independent predictor of $\mathrm{CCC}$ formation. These results indicated that the non-HDL-C/HDL ratio may be used as a noninvasive biomarker for evaluating CCC in CTO patients, and it will be more feasible and economical.

The study has some limitations. First, the assessment of CCC was achieved only using coronary angiography, which is far less accurate than other methods (e.g., CFI). Second, this study was a small retrospective study, and the influence of selection bias cannot be excluded. Finally, Rentrop grade was defined according to the results of coronary angiography, catheter size and the spatial resolution of angiographic systems could influence the results in this study.

\section{Discussion}

CCC exerts protective effects in CTO patients, such as reducing the occurrence of small myocardial infarction, improving ventricular function, decreasing cardiovascular events and increasing long-term survival rate $[6,12$, 13]. The formation of CCC is a complicated process, and several factors contribute to its development. The severity of coronary obstruction and duration of ischemic symptoms positively correlate with poor collateral development [14, 15]. However, patients with diabetes [16], hypercholesterolemia [17], hypertension [18] and hyperuricemia [19] are less likely to develop collateral vessels. However, vascular endothelial growth factor (VEGF) and fibroblast growth factor (FGF) effectively promoted the formation of CCC in animal experiments [20]. The presence and function of CCC were also influenced by plasma chemokine concentrations, such as TNF- $\alpha$ [21], the angiogenic ligand and interferon [22]. Many studies showed that the development of CCC was a pathophysiological process involving multiple mechanisms, including oxidative stress, systematic hypoxia, inflammation and vascular endothelial function [23, 24]. 
Dyslipidemia is a contributing factor for CAD. Hyperlipidemia reduces vascular endothelial function and inhibits CCC formation [25]. However, different components in blood lipids have different impacts on endothelial function. Non-high-density lipoprotein cholesterol includes all atherogenic cholesterol in the blood, and the most important component of which is LDL-C because increased LDL-C causes damage to vascular endothelial function[26]. The incidence of long-term major adverse cardiovascular events (MACE) increased with increasing levels of non-HDL-C after acute myocardial infarction compared to lowering LDL-C to target [27]. Therefore, the lowering of non-HDL-C is a goal of treatment in the process of anti-atherosclerosis [28]. HDL-C exerts a protective role in the pathophysiological process of atherosclerosis formation and development [29], in which HDL-C plays anti-inflammatory and anti-oxidative roles and protects vascular endothelial cells by carried antioxidant enzymes such as paraoxonase-1(PON1), lecithin cholesterol acyltransferase(LCAT), and platelet-activating factor acetylhydrolase (PAF-AH). In particular, PON1 has been suggested to mainly mediate the potential antiatherogenic capacity of HDL [30-32]. The above research suggested that HDL-C and LDL-C played pivotal roles in the physical function of endothelial cells, and endothelial cells are truly involved in the formation of CCC. HDL-C and LDL-C may affect the functioning of endothelial cells, the formation and function of CCC.

Some studies indicated that lipoprotein ratios were better predictors of CAD than parameters of conventional lipids [9]. Our previous study showed that non-HDL-L/ apolipoprotein A-I was highly correlated with the severity of coronary artery lesions and served as a biomarker in the assessment of CAD [33]. Based on the mechanisms and roles of non-HDL-C and HDL-C in the process of atherosclerosis, non-HDL-C/HDL ratio may be an important indicator and predictor of lipid-related disease. Wang et al. reported that the non-HDL-C/HDL ratio was associated with increased non-alcoholic steatohepatitis [34]. Several studies also reported that the non-HDL-C/ HDL ratio was an independent factor of insulin resistance, metabolic syndrome and chronic kidney disease [35]. Some studies examined the role of the non-HDL$\mathrm{C} / \mathrm{HDL}$ ratio in postmenopausal women, and it could be used to predict the risk of CAD because the ratio was higher in females with carotid atherosclerotic plaque [36, 37]. However, there are few studies focusing on the relationship between this ratio and CCC formation.

The present study used the Rentrop grade to assess the formation of CCC. A negative correlation between the non-HDL-C/HDL ratio and Rentrop grade was found.
CCC formation became poorer with increases in the non-HDL-C/HDL ratio. A multivariate logistic regression model showed that the non-HDL-C/HDL ratio was an independent risk factor for the formation of CCC. ROC results indicated that the optimal cut-off value of this ratio was 2.77 for detecting poor formation of CCC, the AUC (0.611) is not very impressive,somehow it has a relatively high sensitivity (77.5\%), comparing with non-HDL-C or HDL respectively, non-HDL-C/HDL ratio was better for predicting CCC poor formation. In clinical practice, non$\mathrm{HDL} / \mathrm{HDL}$ ratio is easy to obtain and more economical than other methods (e.g. CFI, contrast echocardiography). The degree of coronary artery stenosis was tightly related to CCC formation because it promotes the initiation and is the main determinant of the CCC formation. After the formation of CCC is initiated, the function of endothelial cells could affect the function of CCC. Serum HDL-C and LDL-C levels affect vascular endothelial function. The nonHDL-C/HDL ratio was negatively related to CCC formation in the present study. It may be speculated that these two lipid particles affect endothelial cell function. In conclusion, our study provides a new index to assess and predict the formation of CCC.

The present study provides a theoretical basis for the choosing of lipid-lowering drugs for treating CAD. Lipidlowering therapy should not only emphasize the reduction of non-HDL-C but also focus on increasing the level of HDL-C. The treatment of CAD should consider the formation and function of CCC.

\section{Conclusion}

The non-HDL-C/HDL ratio in the CCC poorly formed group of CTO patients was significantly elevated compared to the CCC well-formed group. Non-HDL-C/HDL negatively correlated with CCC formation, it independently served as a better predictive factor of $\mathrm{CCC}$ formation than non-HDL-C or HDL alone, which may be used as a biomarker for the evaluation of CCC.

\section{Abbreviations \\ Non-HDL-C/HDL: Non-high-density lipoprotein cholesterol/high-density lipoprotein cholesterol ratio; CCC: Coronary collateral circulation; CTO: Chronic total occlusive disease; ROC: Receiver operating characteristic; CTOs: Chronic total occlusions; CAD: Coronary artery disease; LDL-C: Low-density lipoprotein cholesterol; non-HDL-C: Nonhigh-density lipoprotein cholesterol; TG: Triglycer- ide; HDL-C: High-density lipoprotein cholesterol; Cl: Confidence interval. \\ Acknowledgements \\ Not applicable. \\ Authors' contributions \\ $Y L$ designed the study and drafted the manuscript. XC collected the data. $S L, Y M, J L$ and $M L$ helped implement and analyze the project. JW reviewed the interpretation of the results, revised the manuscript and decided the}


final version to be published. All of the authors read and approved the final manuscript.

\section{Funding}

This study was supported by the Innovation and Technology Fund of Zhongnan Hospital, Wuhan University (Grant Number cxpy20160027).

\section{Availability of data and materials}

All data generated or analyzed during this study are included in this published article.

\section{Declarations}

\section{Ethics approval and consent to participate}

The ethics committee of Zhongnan Hospital of Wuhan University approved this study, and the informed consent was obtained from all participates.

\section{Consent for publication}

Not applicable.

\section{Competing interests}

The authors declare that they have no competing interests.

\section{Author details}

'Department of Cardiology, Zhongnan Hospital of Wuhan University, No 169 Donghu Road, Wuchang District, Wuhan 430071, Hubei Province, China. ${ }^{2}$ Department of Cardiology, The Central Hospital of Enshi Tujia and Miao Autonomous Prefecture, Enshi 445000, China. ${ }^{3}$ Department of Cardiology, Hubei Jianghan Oilfield General Hospital, Qianjiang 433100, China.

Received: 2 April 2021 Accepted: 18 June 2021

Published online: 23 June 2021

\section{References}

1. Cheney A, Kearney KE, Lombardi W. Sex-based differences in chronic total occlusion management. Curr Atheroscler Rep. 2018;20(12):60.

2. Kahn JK. Angiographic suitability for catheter revascularization of total coronary occlusions in patients from a community hospital setting. Am Heart J. 1993;126(3 Pt 1):561-4.

3. Georgios S, Gerald SW, Alfredo RG, Michail IP, Javier E, David HS, et al. Recanalisation of chronic total coronary occlusions: 2012 consensus document from the EuroCTO club. Eurolntervention. 2012;8(1):139-45.

4. Minh NV, Emmanouil SB, Malek K, Amir R. Physiologic significance of coronary collaterals in chronic total occlusions. Can J Physiol Pharmacol. 2015;93(10):867-71.

5. Pascal M, Stephan HS, Alexandra JL, Adam T, Bertram P, Christian S. The collateral circulation of the heart. BMC Med. 2013;11:143.

6. Christian S, Michael S, Bertram P, Pascal M. The human coronary collateral circulation: development and clinical importance. Eur Heart J. 2013;34(34):2674-82.

7. Pascal M, Harry H, Alexandra JL, Guido K, Bertram P, Christian S. The impact of the coronary collateral circulation on mortality: a meta-analysis. Eur Heart J. 2012;33(5):614-21.

8. Se WK, Jae HJ, Hye JK, Sang-Man J, Sunghwan S, Ji CB, et al. Non-HDLcholesterol/HDL-cholesterol is a better predictor of metabolic syndrome and insulin resistance than apolipoprotein B/apolipoprotein A1. Int J Cardiol. 2013;168(3):2678-83.

9. Li Z, Zhan L, Liren Z, Xiaoxiao O, Yang Y, Wenfeng H, et al. Lipoprotein ratios are better than conventional lipid parameters in predicting coronary heart disease in Chinese Han people. Kardiol Pol. 2015;73(10):931-8.

10. John GH, Theodore AB, Thomas MB, Ralph GB, John EBJ, James AB, et al. ACCF/ AHAVSCAI 2013 update of the clinical competence statement on coronary artery interventional procedures: a report of the American College of Cardiology Foundation/American Heart Association/American College of Physicians
Task Force on Clinical Competence and Training (Writing Committee to Revise the 2007 Clinical Competence Statement on Cardiac Interventional Procedures). J Am Coll Cardiol. 2013;62(4):357-96.

11. Rentrop KP, Cohen M, Blanke H, Phillips RA. Changes in collateral channel filling immediately after controlled coronary artery occlusion by an angioplasty balloon in human subjects. J Am Coll Cardiol. 1985;5(3):587-92.

12. Michael B, Patrik K, Franz RE, Stephan W, Bernhard M, Christian S. Physiologically assessed coronary collateral flow and adverse cardiac ischemic events: a follow-up study in 403 patients with coronary artery disease. J Am Coll Cardiol. 2002;40(9):1545-50.

13. Xiao-Xin S, Shuheng L, Wei F, Yue-Qin T, Rui S, Hongxing W, et al. Preserved myocardial viability in patients with chronic total occlusion of a single coronary artery. J Nucl Cardiol. 2020. https://doi.org/10.1007/s12350-020-02134-z.

14. Börekçi A, Gür M, Şeker T, Baykan AO, Özaltun B, Karakoyun S, et al. Coronary collateral circulation in patients with chronic coronary total occlusion; its relationship with cardiac risk markers and SYNTAX score. Perfusion. 2015;30(6):457-64

15. Gerald SW. The role of coronary collaterals in chronic total occlusions. Curr Cardiol Rev. 2014;10(1):57-64.

16. Ying S, Feng HD, Yang D, Xiao OW, Rui YZ, Lin L, et al. Reduced coronary collateralization in type 2 diabetic patients with chronic total occlusion. Cardiovasc Diabetol. 2018;17(1):26

17. Fan Y, Hu J-S, Guo F, Lu Z-B, Xia H. Lipoprotein(a) as a predictor of poor collateral circulation in patients with chronic stable coronary heart disease. Braz J Med Biol Res. 2017;50(8):e5979.

18. J Koerselman, PPTh de Jaegere, MC Verhaar, Y van der Graaf, DE Grobbee, SMART Study Group. High blood pressure is inversely related with the presence and extent of coronary collaterals. J Hum Hypertens. 2005;19(10):809-17.

19. Onur KU, Durmus YS, Mustafa D, Caner T, Arafat Y, Zafer E, et al. Association between uric acid and coronary collateral circulation in patients with stable coronary artery disease. Angiology. 2014;65(3):227-31.

20. Gabor MR. Angiogenic gene therapy for refractory angina. Expert Opin Biol Ther. 2016;16(3):303-15.

21. Seiler C, PohlT, Billinger M, Meier B. Tumour necrosis factor al pha concentration and collateral flow in patients with coronary artery disease and normal systolic left ventricular function. Heart. 2003;89(1):96-7.

22. Ellen CK, J RM, Ling L, Lawrence WG, Lewis CL, Michael R, et al. Plasma chemokine levels are associated with the presence and extent of angiographic coronary collaterals in chronic ischemic heart disease. PLoS One. 2011;6(6):21174.

23. Onur KU, Caner T, Durmus YS, Mustafa D, Arafat Y, Zafer E, et al. The relationship between neutrophil-to-lymphocyte ratio and coronary collateral circulation. Clin Appl Thromb Hemost. 2015;21(4):329-33.

24. Anurag J, Cody J, Feng D, Devan C, Molly E, William MC, et al. Cardioprotection during ischemia by coronary collateral growth. Am J Physiol Heart Circ Physiol. 2019;316(1):H1-9.

25. J Duan, T Murohara, H Ikeda, A Katoh, S Shintani, K Sasaki. Hypercholesterolemia inhibits angiogenesis in response to hindlimb ischemia: nitric oxidedependent mechanism. Circulation. 2000;102(19 Suppl 3):III370-6.

26. Pierdomenico SD, Costantini F, Bucci A, De Cesare D, Cuccurullo F, Mezzetti A. Low-density lipoprotein oxidation and vitamins $\mathrm{E}$ and $\mathrm{C}$ in sustained and white-coat hypertension. Hypertension. 1998;31(2):621-6.

27. Wanwarang W, Satjatham S, Siriluck G, Arintaya P. Is non-HDL-cholesterol a better predictor of long-term outcome in patients after acute myocardial infarction compared to LDL-cholesterol? : a retrospective study. BMC Cardiovasc Disord. 2017;17(1):10

28. Expert Panel on Detection, Evaluation, and Treatment of High Blood Cholesterol in Adults. Executive Summary of The Third Report of The National Cholesterol Education Program (NCEP) Expert Panel on Detection, Evaluation, And Treatment of High Blood Cholesterol In Adults (Adult Treatment Panel III). JAMA. 2001;285(19):2486-97.

29. Robert SR, H BBJ, W SD, Zahi AF, Valentin F, James G, et al. Cholesterol efflux and atheroprotection: advancing the concept of reverse cholesterol transport. Circulation. 2012;125(15):1905-19.

30. Jin SP, Kwang SC, Hye WL, Jun-Hyok O, Jung HC, Han CL. Predictive and protective role of high-density lipoprotein cholesterol in acute myocardial infarction. Cardiol J. 2019;26(2):176-85. 
31. Meliana R, UIf L. High density lipoproteins and endothelial functions: mechanistic insights and alterations in cardiovascular disease. J Lipid Res. 2013;54(12):3227-43

32. Kerry-Anne R, Philip JB. Antiinflammatory actions of HDL: a new insight. Arterioscler Thromb Vasc Biol. 2008;28(11):1890-1.

33. Ya L, Shu L, Yulin M, Jialing L, Mingying L, Jing W. Relationship between nonhigh-density lipoprotein cholesterol/apolipoprotein A-I and monocyte/highdensity lipoprotein cholesterol ratio and coronary heart disease. Coron Artery Dis. 2020;31(7):623-7.

34. Dianhui W, Ling W, Zhanqing W, Shihong C, Yihong N, Dongqing J. Higher non-HDL-cholesterol to HDL-cholesterol ratio linked with increased nonalcoholic steatohepatitis. Lipids Health Dis. 2018;17(1):67.
35. Jia W, Yiyin C, Yun H, Yao L, Xing L, Honghao Z, et al. Association of the TG/ $\mathrm{HDL}-\mathrm{C}$ and Non-HDL-C/HDL-C ratios with chronic kidney disease in an adult Chinese population. Kidney Blood Press Res. 2017;42(6):1141-54.

36. Ting-Ting W, Ying G, Ying-Ying Z, Yi-Tong M, Xiang X. Atherogenic index of plasma (AIP): a novel predictive indicator for the coronary artery disease in postmenopausal women. Lipids Health Dis. 2018;17(1):197.

37. Masson W, Epstein T, Huerín M, Lobo M, Molinero G, Siniawski D. Association between non-HDL-C/HDL-C ratio and carotid atherosclerosis in postmenopausal middle-aged women. Climacteric. 2019;22(5):518-22.

\section{Publisher's Note}

Springer Nature remains neutral with regard to jurisdictional claims in published maps and institutional affiliations.
Ready to submit your research? Choose BMC and benefit from:

- fast, convenient online submission

- thorough peer review by experienced researchers in your field

- rapid publication on acceptance

- support for research data, including large and complex data types

- gold Open Access which fosters wider collaboration and increased citations

- maximum visibility for your research: over 100M website views per year

At BMC, research is always in progress.

Learn more biomedcentral.com/submissions 